\title{
Incidence rate and antibiotic resistance profile of Cronobacter sakazakii isolated from various food products
}

\author{
*Tayeb, B.A., Mohamed Sharif, Y.H. and Ameen, A.M. \\ Food Microbiology Unit, Department of Laboratory, Directorate of Veterinary in Duhok, Jn 1,1000 Galy \\ Way, Duhok, Kurdistan region of Iraq
}

\begin{abstract}
Article history:
Received: 27 June 2020

Received in revised form: 18 July 2020

Accepted: 9 August 2020

Available Online: 30

September 2020

\section{Keywords:}

Antibiotic resistance,

Cronobacter sakazakii,

Food products,

Molecular detection
\end{abstract}

\section{DOI:}

https://doi.org/10.26656/fr.2017.4(6).304

\begin{abstract}
Cronobacter sakazakii (C. sakazakii) is a foodborne pathogen which has been linked to various food outbreaks. The current study was aimed to isolate and identify this pathogen from different kind of food products and herbs as well as to reveal its antibacterial resistant profiling. A total of 235 samples were collected, including 130 Powdered Infant Formula (PIF), 55 spices and herbs and 50 samples from Bouillon Flavoured Powder (BFP). These samples were obtained from local markets in Duhok city of Iraq from February to August 2019. The collected items were checked for the presence of $C$. sakazakii by using conventional biochemical tests and confirmed through molecular techniques. The findings showed that $3.1 \%$ of PIF, $24 \%$ of BFP and $78.2 \%$ of spices and herbs were positive for $C$. sakazakii. This bacterium expressed a complete susceptibility to each of ampicillin, tetracycline, gentamycin and chloramphenicol and showed high to mild resistance to the rest of the examined antibiotics Microbiological evaluation of imported food is crucial for safeguarding public health. The high contamination rate and high drug-resistant $C$. sakazakii in the examined food products declared prospective hazards to endangered people.
\end{abstract}

\section{Introduction}

C. sakazakii, formerly named as yellow-pigmented E. cloacae, is one of the seven species of Cronobacter spp, and it was first discovered as a new species in 1980 (Farmer et al., 1980). It is a gram negative, rod shape, non-spore forming bacteria and belongs to the family Enterobacteriaceae. This bacterium has strong association with foodborne diseases (Iversen and Forsythe 2004). C. sakazakii causes severe infection like meningitis and entero-colitis in neonates and infants especially in premature babies (Bar-Oz et al., 2001). The International Commission for Microbiological Specifications for Foods (ICMSF, 2002) has categorized C. sakazakii as 'severe hazard for restricted populations, life-threatening or substantial chronic sequelae or long duration'. This could be due to the fact that this organism is considered as a new emerging and an aggressive pathogen in endangered people such as children and elderly (Hunter and Bean 2013; Hariri at al., 2013). In fact, the reports show that the prevalence and severity of the disease are much higher in children than in any other groups (Hariri et al., 2013).

C. sakazakii has been isolated from many different food items such as fruits and vegetables, starches, herbs, and spices. Moreover, other food products have also been reported to be contaminated with this organism like animal foods, milk, fish, meat and other sub-productions like powdered infant food (PIF) and these food sources have been associated with $C$. sakazakii outbreaks (FAO/ WHO 2008; Lee et al., 2012).

Nowadays, there is more food safety awareness about $C$. sakazakii worldwide as the globalization of food chain brings a wider range of foodborne pathogens (Shukla et al., 2016). The pressing problem with $C$. sakazakii is the development of antibiotic resistance, which has been confirmed (Lai, 2001). The antibiotic treatment of this dangerous pathogen is quite limited. Furthermore, the infective dose for C. sakazakii infection is also low compared to other foodborne pathogens which making it some kinds of difficulty to control or minimize the infection. Therefore, the actions should be taken for alternative antibiotic therapy or biocontrol and tough monitoring is essential for this bacterium (Lehner et al., 2004).

In recent years, various detection methods have been applied and developed for isolation and identification of 
C. sakazakii in food and environmental samples (Shukla et al., 2016). Traditional culture-based procedures, like sample preparation, pre-enrichment, plating out, and conventional biochemical tests are widely used for the isolation and identification of this pathogen in food products and environmental samples. However, the drawback of this technique is labor-intensive. Nevertheless, traditional cultural methods are reliable and sensitive enough so that it is still used in many different laboratories. Some other emerging new techniques are now being used for the detection of $C$. sakazakii. Traditional Polymerase Chain Reaction (PCR) or Real-time PCR (qPCR), are both forms of molecular techniques used for identification of this pathogen. They are more sensitive, specific and can detect the organism in reasonably low abundance in a very short time ( $\mathrm{Si}$ et al., 2016).

The current study was aimed to isolate, identify and reveal the antimicrobial susceptibility of $C$. sakazakii in different type of imported food including PIF, Bouillon Flavored Powder (BFP) and herbs and spices by using cultural- and PCR-based techniques in Duhok city, Iraq.

\section{Materials and methods}

\subsection{Sample collection}

A total of one hundred thirty samples of PIF were collected from different retail markets in Duhok city. Those PIF items were imported from abroad and the cans belong to famous international trademarks. The physical condition, whether leaked or rusted and the expiry date of the cans was checked. Any cans within three months of expiry dates were excluded from the study. In addition, 55 samples from a different type of herbs and spices were obtained from different shops in the city center of Duhok city. These spices include Cardamom $(\mathrm{n}=10)$, Wild thyme $(\mathrm{n}=5)$, Cummins $(\mathrm{n}=8)$, Oregano herb $(n=8)$, Turmeric powder $(n=12)$, Crushed peppers $(n=12)$. Furthermore, fifty samples of Bouillon Flavoured Powder (BFP) in two shape forms either cubes $(n=25)$ or powdered $(n=25)$ originating from six different countries including Turkey, India, China, USA, Syria and UAE were also collected from various local shops for isolation of C. sakazakii.

\subsection{Enrichment}

The method that used for the isolation and identification of $C$. sakazakii in this research was the official techniques of the International Standard Organization (ISO) 22964:2017(E) with a minor modification. Briefly, $10 \mathrm{~g}$ of each of the collected sample weighed separately and aseptically transferred into a bottle containing $90 \mathrm{~mL}$ of pre-warmed buffered peptone water (BPW), (HiMedia Laboratories, India).
The aliquots were mixed well by vortex for $30 \mathrm{~s}$ and incubated at $37^{\circ} \mathrm{C}$ for $24 \pm 2 \mathrm{hrs}$. From the previous step (cultured buffered peptone water), $0.1 \mathrm{~mL}$ was transferred to a tube containing $10 \mathrm{~mL}$ of modified Lauryl Sulphate Tryptose Broth Base (mLST) (Oxoid, England) containing vancomycin $(5 \mathrm{mg} / 100 \mathrm{~mL})$. The selective suspension (mLST suspension) was then incubated at $44 \pm 0.5^{\circ} \mathrm{C}$ for $24 \pm 2 \mathrm{hrs}$.

\subsection{Isolation of C. sakazakii}

About $10 \mu \mathrm{L}$ from the enriched step was taken and inoculated on Enterobacter sakazakii Isolation Agar (ESIA), (Oxoid, England) and the plates were incubated at $44^{\circ} \mathrm{C} \pm 0.5^{\circ} \mathrm{C}$ for $24 \pm 2 \mathrm{hrs}$ (Miranda et al., 2017). The typical colonies of $C$. sakazakii on ESIA give bluish green in color (Weber et al., 2009). Therefore, the presumptive colonies were selected to inoculate of Trypticase Soy Agar (TSA) (HiMedia, India) and incubated overnight at $37^{\circ} \mathrm{C}$. Cronobacter sakazakii produces yellow pigmentation on this agar (Weber et al., 2009).

\subsection{VITEK-2 Systems}

The suspected colonies of $C$. sakazakii were picked and suspended into a tube containing $3.0 \mathrm{~mL}$ of $45 \%$ sodium chloride solution. The bacterial suspension turbidity was adjusted by using VITEK Densicheck (bioMerieux) to become $0.5 \mathrm{McF}$ arland standards. After that, the ID-Gram Negative (ID-GN) was used by using VITEK-2 system following manufacturer manual steps (BioMerieux, France) (Ling et al., 2003).

\subsection{Molecular confirmation}

The presumptive colonies of $C$. sakazakii from the TSA plates were confirmed by using PCR techniques according to HumPCR $^{\mathrm{TM}}$ Cronobacter sakazakii Detection Kit (Bioingentech, Chile).

\subsubsection{DNA extraction}

DNA was extracted from cell suspension using QIAamp DNA Mini kit (Qiagen, Germany). Briefly, a loopful of suspected colonies grown on the agar plates was picked and suspended into $2 \mathrm{~mL}$ of distilled water in an eppendorf tube. The suspension was then centrifuged for 5 mins at $2000 \mathrm{rpm}$ and the supernatant was then removed without disturbance of the cell pellet. The pellet was resuspended with $200 \mu \mathrm{L}$ of distilled water then 20 $\mu \mathrm{L}$ of QIAGEN proteinase $\mathrm{K}$ was added. The suspension was incubated in a water bath at $56^{\circ} \mathrm{C}$ and then $200 \mu \mathrm{L}$ of the absolute ethanol was added to the mixture. After centrifugation, the mixture was placed in a QIAamp Mini spin column clean $2 \mathrm{~mL}$ collection tube and again centrifuged at $8000 \mathrm{rpm}$ for $1 \mathrm{~min}$. The collection tube 
was removed and replaced by a new one and then $500 \mu \mathrm{L}$ of Buffer AW1 was added to the mixture and microcentrifuged at $8000 \mathrm{rpm}$ for $1 \mathrm{~min}$. Five hundred $\mu \mathrm{L}$ of Buffer AW2 was added to the tube and centrifuged for $3 \mathrm{~min}$ at $14,000 \mathrm{rpm}$. Before adding the $200 \mu \mathrm{L}$ of elusion buffer from the Tris-EDTA (TE), the collection tube was replaced by a new one and centrifuged at 8000 rpm for 1 min and used as a DNA.

\subsubsection{Amplification of bacterial DNA}

The PCR amplification was carried out in a final volume of $15 \mu \mathrm{L}$ consisting of $6 \mu \mathrm{L}$ of $\mathrm{C}$. sakazakii premixture (MasterMix), $3 \mu \mathrm{L}$ of extracted DNA from $C$. sakazakii positive colonies and $6 \mu \mathrm{L}$ DNase free water. The positive, negative and internal controls were also used at each running time and composed from the same volume as previous. Each reaction tube was covered with $5 \mu \mathrm{L}$ of mineral oil. The tubes were placed in a thermo cycler (Applied Biosystems, USA) and the PCR cycling conditions are shown in Table 1.

Table 1. PCR cycling condition

\begin{tabular}{cccc}
\hline No. of cycles & PCR cycle & Temperature & Time \\
\hline \multirow{2}{*}{1 cycle } & Initial denaturation & $94^{\circ} \mathrm{C}$ & $2 \mathrm{~min}$ \\
& Denaturation & $94^{\circ} \mathrm{C}$ & $30 \mathrm{~s}$ \\
30 cycle & Annealing & $57^{\circ} \mathrm{C}$ & $30 \mathrm{~s}$ \\
& Extension & $72^{\circ} \mathrm{C}$ & $30 \mathrm{~s}$ \\
1 cycle & & $72^{\circ} \mathrm{C}$ & $5 \mathrm{~min}$ \\
\hline
\end{tabular}

\subsubsection{Gel electrophoresis}

The PCR products were analyzed in $1.5 \%$ of agarose gel prepared with $1 \times$ Tris-acetate-EDTA (TAE) buffer and stained by red safe DNA staining solution (GeNetBio, Korea). The electrophoresis was run in $1 \mathrm{X}$ TAE buffer by $100 \mathrm{~V}$ for a period of 40 mins. The amplified products were identified under ultra-violet (UV) trans-illuminator.

\subsection{Antimicrobial susceptibility test}

The antibiotic susceptibility test of $C$. sakazakii that isolated from food samples was determined using KirbyBauer disc diffusion method (Bauer et al., 1966) on Mueller Hinton Agar (HiMedia, India). All the isolates were tested for susceptibility against 10 antibiotics including ampicillin $(10 \mu \mathrm{g})$, cephalothin $(30 \mu \mathrm{g})$, chloramphenicol $(30 \mu \mathrm{g})$, gentamicin $(10 \mu \mathrm{g})$, kanamycin $(30 \mu \mathrm{g})$, nalidixic acid $(30 \mu \mathrm{g})$, streptomycin $(10 \mu \mathrm{g})$, tetracycline $(30 \mu \mathrm{g})$, erythromycin $(15 \mu \mathrm{g})$ and norfloxacin $(10 \mu \mathrm{g})$. The diameters of the inhibition zone for each antibiotic was measured and analyzed according to the clinical and laboratory standards institute (CLSI, 2015).

\section{Results}

In the current research, a total of 130 PIF samples were screened for the occurrence of $C$. sakazakii. Only four samples $(3.1 \%)$ have shown to be contaminated with this pathogen. The other species belong to Cronobacter family such as $C$. malonaticus, $C$. Dublinensis and others were also identified in the PIF samples. There were different kinds of spices and herbs included in the present study. In a total of 55 spice and herb samples, only $43(78.2 \%)$ of them showed positive for $C$. sakazakii by both culture types used in this study (Table 2). The colonies of $C$. sakazakii gave bluish green in color on ESIA and yellowish pigmentation on TSA (Figure $1 \mathrm{~A}$ and B). A total of 50 BFP samples, from the cubes or powder bouillons were examined for the presence of C. sakazakii, 12 of them (24\%) showed positive for $C$. sakazakii. The suspected samples were confirmed as positive by traditional culturing methods and biochemical as well as the molecular techniques.

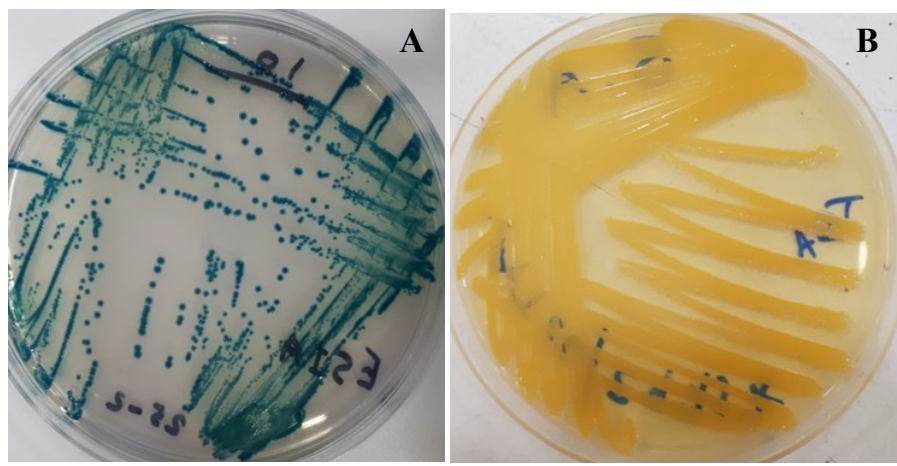

Figure 1. Cronobacter sakazakii colonies on ESIA agar showed blue-green colonies (A), TSA shows yellow pigmentation (B)

\subsection{Confirmation by VITEK-2 System}

This system showed the confidence as excellent identification of selected organism of probability $99 \%$ as C. sakazakii (Figure 2) from most selected colonies. All other isolates from the suspected colonies revealed identification value between $93-98 \%$ of the pathogen.

Table 2. The results of examination of food products with dried herbal and spices for the presence of Cronobacter sakazakii

\begin{tabular}{lccccc}
\hline \multirow{2}{*}{ Samples } & Number of analysed & \multicolumn{2}{c}{ Positive } & \multicolumn{2}{c}{ Negative } \\
\cline { 3 - 6 } & samples & $\mathrm{n}$ & $\%$ & $\mathrm{n}$ & $\%$ \\
\hline Powdered infant formula (PIF) & 130 & 4 & 3.1 & 126 & 96.9 \\
Herbs and spices & 55 & 43 & 78.2 & 12 & 21.8 \\
Bouillon Flavoured Powder (BFP) & 50 & 12 & 24 & 38 & 48 \\
Total & 235 & 59 & 25.1 & 176 & 74.9 \\
\hline
\end{tabular}


Selected Organism

$99 \%$ Probability

Bionumber: 06257300533220

Tonobacter sakazakii

Figure 2. VITEK-2 system photomicrograph shows the excellent identification of $99 \%$ probability of Cronobacter sakazakii in different food items

\subsection{Confirmation by PCR}

Interestingly, all the suspected colonies were identified as positive for C. sakazakii by PCR (Figure 3). Moreover, these colonies were also examined by using VITEK2 system and they showed more than $95 \%$ as $C$. sakazakii.

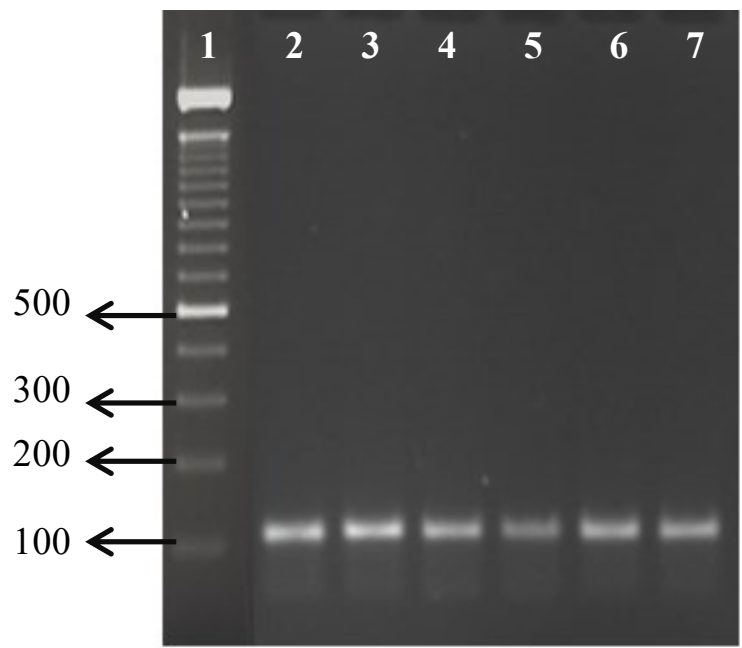

Figure 3. PCR confirmation of C. sakazakii isolates, agarose gel electrophoresis of PCR amplified products from suspected $C$. sakazakii colonies $\sim 115 \mathrm{bp}$ using $1.5 \%$ agarose gel at $100 \mathrm{~V}$ for $40 \mathrm{~min}$. Lane (1): $100 \mathrm{bp}$ DNA ladder, Lane (2-7): PCR products of PCR product size suspected as $C$. sakazakii gene

\subsection{Antibiotic resistance test}

According to antibiotic resistance profiling, most of the tested isolates were shown to be resistant to the tested antibiotics. However, this bacterium was quite susceptible to ampicillin (83.5\%), tetracycline (68.7\%), gentamycin (79.8\%) and chloramphenicol (82.8\%). C.

Table 3. Antibiotic susceptibility of Cronobacter spp. of food isolates

\begin{tabular}{lcccc}
\hline \multirow{2}{*}{ Antibiotics } & $\begin{array}{c}\text { Concentration } \\
\mu \mathrm{g} / \text { disc }\end{array}$ & $\mathrm{S}$ & $\mathrm{R}$ & $\mathrm{I}$ \\
\cline { 3 - 5 } & 10 & 84 & 17 & - \\
\hline Ampicillin & 30 & 83 & 17 & - \\
Chloramphenicol & 30 & 16 & 66 & 18 \\
Cephalothin & 15 & 24 & 46 & 31 \\
Erythromycin & 10 & 80 & 17 & 2.9 \\
Gentamicin & 30 & 15 & 63 & 22 \\
Kanamycin & 30 & 15 & 19 & 67 \\
Nalidixic acid & 10 & 21 & 50 & 28 \\
Streptomycin & 30 & 69 & 25 & - \\
Tetracycline & 10 & 20 & 43 & 37 \\
Norfloxacin & &
\end{tabular}

S: sensitive, R: resistance, I: intermediate. sakazakii found to be high to mild resistance to the rest of the examined antibacterial (Table 3).

\section{Discussion}

C. sakazakii is responsible for severe and deadly infection caused by consumption of contaminated food, even though the lower dose of this bacterium could be life-threatening especially in neonates (Bar-Oz et al., 2001). Additionally, C. sakazakii isolates might exist in a various kind of food and environmental samples (Lee et al., 2012). There have been several discovered traditional methods described for the identification of C. sakazakii (Shukla et al., 2016). It is well known that the use of conventional chromogenic agar media accompanied with confirmatory based PCR test was confirmed to be rapid and useful for screening and isolation of $C$. sakazakii (Chen et al., 2010; Miranda et al., 2017). Therefore, the combination of both chromogenic agar and molecular methods were used in this study to improve the detection efficiency.

Since Iraq is relatively a consumer country and most of its commodities come from abroad, special attention and microbiological quality should be considered related to food safety. According to our knowledge, there is no data available for the existence of this bacterium from food products in our area. Therefore, the current study was aimed to isolate and identify C. sakazakii and assess its antibiotic-resistant profile.

PIF is the most potential source contaminated by $C$. sakazakii (Iversen and Forsythe, 2004). A total of 130 PIF samples, only $3.1 \%$ showed positive by traditional culturing methods and by conventional PCR techniques. The occurrence of $C$. sakazakii in his sample type was relatively low compared to other food products examined in this study. This result was different from previous studies that carried out in Iraq. Two different studies were conducted on imported PIF obtaining from local Iraqi markets, one of them showed a high rate of contamination $(61.8 \%)$ while other was unable to identify this pathogen in this kind of food (Al.Mossawi and Al.joubori, 2015; Jebur and Abood, 2018).

Moreover, the incidence of Cronobacter spp. in PIF showed variance according to geographical areas. For instance, a research from China obtained approximately 2282 PIF and follow-up milk samples and from this only $1.1 \%$ of the examined samples were positive for Cronobacter spp. (Pei et al., 2016). Another previous study performed in the same country which collected about 400 PIF samples and revealed that the positive rate was 11.5\% (Pan et al., 2014). A further experiment performed in the UK on a total of 82 PIF samples only two of them showed positive for $C$. sakazakii (Iversen 
and Forsythe, 2004). The differences in contamination rates between our study and the previous one could be due to the fact that the quality of the imported food to our region is not good enough to be complying with international standards.

The findings of the current study showed the highest incidence rate $(78.2 \%)$ of $C$. sakazakii in herbs and spices compared with other food products included in the study. This rate was higher than that of a previous study which only $15 \%$ of spice and herb samples containing Cronobacter spp. (Ueda, 2017). The results of the present study was on the contrary with those found in a study that analysed 22 samples of spices and only one sample showed positive for this bacterium ( $\mathrm{Li}$ et al., 2014). On the other hand, a study by Jaradat et al. (2009), has found the highest percentage of Cronobacter spp. in spices and herbs compared to other tested food products but there were no positive results in powdered milk (Jaradat et al., 2009). Another experiment showed that half of the examined spice and herb samples were positive for $C$. sakazakii (Belal et al., 2013). The high contamination rate of this bacterium in spices and herbs samples found in this study could be due to that the bacterium has the ability to survive in extremely dry conditions and high temperatures (Breeuwer et al., 2003; Stojanović et al., 2011; Hochel et al., 2012).

BFP cubes or powders are made from dehydrated meat or vegetables and containing of some nutrients like sodium, potassium, carbohydrates (fat) and some vitamins. This kind of food could be used to flavour other dishes like soups, gravies and even add in dry foods such as cooked rice (Morretti et al., 2018). Since it is highly consumed in our country, it should be checked and evaluated for their microbiological quality.

To our knowledge, the BFP has not been evaluated for its contamination rate by microorganisms. This is considered as a part of the objective of the current study for determining the contamination rate in this particular food. Hence, the current study has revealed a relatively high incidence rate of this bacterium in BFP samples. Interestingly, from the total examined of BFP samples, twelve (24\%) showed positive for $C$. sakazakii. This lower microbiological quality of the BFP is an indication that BFP was probably contaminated during or after the manufacturing process. Some researchers have proven that $C$. sakazakii is responsible for meningitis in endangered people like neonates and elderly (Bar-Oz et al., 2001); therefore, microbiological quality of BFP should not be underestimated.

Several previous researchers have studied and confirmed that the Cronobacter spp., including $C$. sakazakii, can be easily eradicated by antibacterial administration (Pérez et al., 2007; Fei et al., 2017). However, there are some factors such as long-term application, quantity and underestimated or sub-lethal dose might lead to the development of antibiotic resistance. Another reason behind the development of antibiotic-resistant is the acquisition of antibioticresistant genes (ARGs) from the surrounding environment or due to the mutational changes in these genes (Langdon et al., 2016; Kardos, 2017). The current study showed that this bacterium was highly sensitive to only four of the examined antibiotics namely ampicillin, tetracycline, gentamycin and chloramphenicol (Table 3). A previous study worked on 19 strains of Cronobacter spp. and revealed that this pathogen is highly resistant to ampicillin which is totally opposite with the data from this study (Fei et al., 2017). However, the findings of the current study are agreed to other previous studies (Molloy et al., 2009; Parra-Flores et al., 2018).

\section{Conclusion}

The findings of the current study revealed that the contamination rate of $C$. sakazakii in food products is high enough to take actions. The microbiological significance evaluation of BFP is not less than PIF samples because of its high incidence rate of $C$. sakazakii. Several methods are needed for isolation, identification and confirmation of this pathogen as none of the traditional culturing, biochemical or molecular techniques are reliable because false negatives or false positives results are inevitable. The evaluation of antibacterial profiling for microorganisms is important to individualise therapy strategies for those who are infected particularly endangered people like neonates and the elderly. If this happened, safety strategy complementation would be easier and control of the disease would be manageable. Consequently, risk assessments of food products, contamination levels and prevent transmission of this bacterium could be evaluated and brought about safer food for communities.

\section{Conflict of interest}

The authors declare no conflict of interest.

\section{Acknowledgments}

We would like to express our sincere gratitude to the laboratory department at the Veterinary directorate in Duhok province for providing the laboratory facility.

\section{References}

Al.Mossawi, M.T. and Al.joubori, Y.S.H. (2015). Detection of Cronobacter sakazakii (Enterobacter 
sakazakii) in powdered food infants (PIF) and raw milk in Iraq. Baghdad Science Journal, 12, 63-71. https://doi.org/10.21123/bsj.12.1.63-71

Bar-Oz, B., Preminger, A., Peleg, O., Block, C. and Arad, I. (2001). Enterobacter sakazakii infection in the newborn. Acta Paediatrics, 90(3), 356-358. https://doi.org/10.1080/080352501300067857

Bauer, A.W., Kirby, W.M.M., Sherris, J.C. and Turck, M. (1966). Antibiotic susceptibility testing by a standardised single disk method. American Journal of Clinical Pathology, 45(4), 493-496. https:// doi.org/10.1093/ajcp/45.4_ts.493

Belal, M., Al-Mariri, A., Hallab, L. and Hamad, I. (2013). Detection of Cronobacter spp. (formerly Enterobacter sakazakii) from medicinal plants and spices in Syria. Journal of Infection in Developing Countries, 7, 82-89. https://doi.org/10.3855/ jidc. 2222

Breeuwer, P., Lardeau, A. Peterz, M. and Joosten, H.M. (2003). Desiccation and heat tolerance of Enterobacter sakazakii. Journal of Applied Microbiology, 95(5), 967-973. https:// doi.org/10.1046/j.1365-2672.2003.02067.x

Chen, Y.I., Song, K.Y., Brown, E.W. and Lampel, K.A. (2010). Development of an Improved Protocol for the Isolation and Detection of Enterobacter sakazakii (Cronobacter) from Powdered Infant Formula. Journal of Food Protection, 73(6), 10161022. https://doi.org/10.4315/0362-028X-73.6.1016

CLSI. (2015). Performance standards for antimicrobial susceptibility testing; Twenty-Fifth Informational Supplement. CLSI Document M100-S25. Wayne, PA, USA: CLSI.

Moretti, D., Hurrell, R.F. and Cercamondi, C.I. (2018). Chapter 16 - Bouillon Cubes. In Mannar, M.G.V. and Hurrell, R.F. (Eds.). Food Fortification in a Globalized World, p. 159-165. USA: Academic Press. https://doi.org/10.1016/B978-0-12-8028612.00016-X

Fanning, S. and Forsythe, S. (2008). Isolation and identification of Enterobacter sakazakii. In Ferber, J.M., Forsynthe, S.J. and Doyle, M.P. (Eds.). Enterobacter sakazakii, p. 27-59. USA: ASM Press. https://doi.org/10.1128/9781555815608.ch2

Farmer, J.J., Asbury, A., Hickman, F.W. and Brenner, D.J. (1980). Enterobacter sakazakii: a new species of "Enterobacteriaceae" isolated from clinical specimens. International Journal Syst Bacteriology, 30(3), 569- 584. https://doi.org/10.1099/0020771330-3-569

Fei, P., Jiang, Y., Feng, J., Forsythe, S.J., Li, R. and Zhou, Y. (2017). Antibiotic and desiccation resistance of Cronobacter sakazakii and $C$. malonaticus isolates from powdered infant formula and processing environments. Frontiers in Microbiology, 8, 316. https://doi.org/10.3389/ fmicb.2017.00316

Food and Agriculture Organization and World Health Organization [FAO/WHO]. (2008). Enterobacter sakazakii (Cronobacter spp.) in Powdered FollowUp Formulae. Microbiological Risk Assessment. Series No. 15. Rome: FAO.

Hariri, S., Joseph, S. and Forsythe, S.J. (2013). Cronobacter sakazakii ST4 strains and neonatal meningitis, United States. Emergency Infectious Disease, 19, 175-177. https://doi.org/10.3201/ eid1901.120649

Hochel, I., Růžičková, H., Krásný, L. and Demnerová, K. (2012). Occurrence of Cronobacter spp. in retail foods. Journal of Applied Microbiology, 112(6), 1257-1265. https://doi.org/10.1111/j.13652672.2012.05292.x

Hunter, C.J. and Bean, J.F. (2013). Cronobacter: an emerging opportunistic pathogen associated with neonatal meningitis, sepsis and necrotizing enterocolitis. Journal Perinatology, 33, 581-585. https://doi.org/10.1038/jp.2013.26

Iversen, C. and Forsythe, S. (2004). Isolation of Enterobacter sakazakii and other Enterobacteriaceae from powdered infant formula milk and related products. Food Microbiology, 21 (6), 771-777. https://doi.org/10.1016/ j.fm.2004.01.009

Jaradat, Z.W., Ababneh, Q.O., Saadoun, I.M., Samara, N.A. and Rashdan, A.M. (2009). Isolation of Cronobacter spp. (formerly Enterobacter sakazakii) from infant food, herbs and environmental samples and the subsequent identification and confirmation of the isolates using biochemical, chromogenic assays, PCR and $16 \mathrm{~S}$ rRNA sequencing. $B M C$ Microbiology, 9, 225. https://doi.org/10.1186/14712180-9-225

Jebur, D.M. and Abood, Z.H. (2018). Isolation and Detection of Cronobacter sakazakii from Infant Dried Milk using PCR and RT-PCR techniques. Iraqi Journal of Biotechnology, 17, 91-99

Kardos, N. (2017). Overuse of antibiotics and antibiotic resistance in medical applications featuring carbapenemase resistant Enterobacteriaceae (CRE). SOJ Microbiol Infectious Disease, 5(5), 1-27. https://doi.org/10.15226/sojmid/5/5/00183

Lai, K.K. (2001). Enterobacter sakazakii infections among neonates, infants, children, and adults. Case reports and a review of the literature. Medicine, 80 
(2), 113-122. https://doi.org/10.1097/00005792200103000-00004

Langdon, A., Crook, N. and Dantas, G. (2016). The effects of antibiotics on the microbiome throughout development and alternative approaches for therapeutic modulation. Genome Medicine, 8, 39. https://doi.org/10.1186/s13073-016-0294-z

Lee, Y.D., Park, J.H. and Chang, H. (2012). Detection, antibiotic susceptibility and biofilm formation of Cronobacter spp. from various foods in Korea. Food Control, 24(1-2), 225-230. https://doi.org/10.1016/ j.foodcont.2011.09.023

Lehner, A., Tasara, T. and Stephan, R. (2004). 16S rRNA gene based analysis of Enterobacter sakazakii strains from different sources and development of a PCR assay for identification. BMC Microbiology, 4, 4-43. https://doi.org/10.1186/1471-2180-4-43

Li, Y., Chen, Q., Zhao, J., Jiang, H., Lu, F., Bie, X. and $\mathrm{Lu}, \quad Z$. (2014). Isolation, identification and antimicrobial resistance of Cronobacter spp. isolated from various foods in China. Food Control, 37, 109114. https://doi.org/10.1016/j.foodcont.2013.09.017

Ling, T.K.W., Lin, Z.K. and Cheng, A.F.B. (2003). Evaluation of the VITEK2 system for rapid direct identification and susceptibility testing of gram negative bacilli from positive blood cultures. Journal of Clinical Microbiology, 41, 4705-4707. https:// doi.org/10.1128/JCM.41.10.4705-4707.2003

Miranda, N., Banerjee, P., Simpson, S., Kerdahi, K. and Sulaiman, I. (2017). Molecular Surveillance of Cronobacter spp. Isolated from a Wide Variety of Foods from 44 Different Countries by Sequence Typing of 16S rRNA, rpoB and O-Antigen Genes. Foods, $\quad$ 6(5), $\quad 36 . \quad$ https://doi.org/10.3390/ foods 6050036

Molloy, C., Cagney, C., O’Brien, S., Iversen, C., Fanning, S. and Duffy, G. (2009). Surveillance and characterization by pulsed-field gel electrophoresis of Cronobacter spp. in farming and domestic environments, food production animals and retails foods. International Journal Food Microbiology, 136(2), 198-238.

Pan, Z., Cui, J., Lyu, G., Du, X., Ain, L., Guo, Y., Xu, B., Li, W., Cui, Z. and Zhao, C. (2014). Isolation and molecular typing of Cronobacter spp. in commercial powdered infant formula and follow up formula. Foodborne Pathogen Diseases, 11, 456-461. https:// doi.org/10.1089/fpd.2013.1691

Parra-Flores, J., Aguirre, J., Juneja, V., Jackson, E.E., Cruz-Córdova, A., Silva-Sanchez, J. and Forsythe, S. (2018). Virulence and Antibiotic Resistance Profiles of Cronobacter sakazakii and Enterobacter spp.
Involved in the Diarrheic Hemorrhagic Outbreak in Mexico. Frontiers in Microbiology, 9, 2206. https:// doi.org/10.3389/fmicb.2018.02206

Pei, X.Y., Yan, L., Zhu, J.H., Li, N., Guo, Y.C., Fu, P., Jia, H Y., Zhang, X.L., Tang, X.R. and Yang, D.J. (2016). The survey of Cronobacter spp. (formerly Enterbacter sakazakii) in infant and follow up powdered formula in China in 2012. Biomedical and Environmental Sciences, 29(2), 99-106.

Pérez, A., Canle, D., Latasa, C., Poza, M., Beceiro, A. and Tomás, M., (2007). Cloning, nucleotide sequencing, and analysis of the AcrAB-TolC efflux pump of Enterobacter cloacae and determination of its involvement in antibiotic resistance in a clinical isolate. Antimicrobial Agents Chemotherapy, 51, 3247-3253. https://doi.org/10.1128/AAC.00072-07

Shukla, S., Lee, G., Song, X., Park, J.H., Cho, H., Lee, E.J. and Kim, M. (2016). Detection of Cronobacter sakazakii in powdered infant formula using an immunoliposome-based immunomagnetic concentration and separation assay. Scientific Reports 6, 34721. https://doi.org/10.1038/srep34721

Si, Y., Grazon, C., Clavier, G., Rieger, J., Audibert, J.F., Sclavi, B. and Méallet-Renault, R. (2016). Rapid and accurate detection of Escherichia coli growth by fluorescent $\mathrm{pH}$ sensitive organic nanoparticles for high throughput screening applications. Biosens Bioelectron, 75, 320-327. https://doi.org/10.1016/ j.bios.2015.08.028

Stojanović, M.M., Katić, V. and Kuzmanović, J. (2011). "Isolation of Cronobacter Sakazakii from Different Herbal Teas". Vojnosanitetski Pregled, 68(10), 837841. https://doi.org/10.2298/VSP1110837S

Ueda, S. (2017). Occurrence of Cronobacter spp. in Dried Foods, Fresh Vegetables and Soil. Biocontrol Science, 22(1), 55-60. https://doi.org/10.4265/ bio. 22.55

Weber, C., Stephan, R., Druggan, P., Joosten, H. and Iversen, C. (2009). Improving the enrichment procedure for Enterobacteriaceae detection. Food Microbiology, 26(6), 565-72. https:// doi.org/10.1016/j.fm.2009.03.010 